\title{
Efficiency, Equity, and Timing of Voting Mechanisms
}

\author{
MARCO BATTAGLINI Princeton University \\ REBECCA MORTON New York University \\ THOMAS PALFREY California Institute of Technology
}

\begin{abstract}
TJe compare the behavior of voters under simultaneous and sequential voting rules when voting $\checkmark$ is costly and information is incomplete. In many political institutions, ranging from small committees to mass elections, voting is sequential, which allows some voters to know the choices of earlier voters. For a stylized model, we generate a variety of predictions about the relative efficiency and participation equity of these two systems, which we test using controlled laboratory experiments. Most of the qualitative predictions are supported by the data, but there are significant departures from the predicted equilibrium strategies, in both the sequential and the simultaneous voting games. We find a tradeoff between information aggregation, efficiency, and equity in sequential voting: a sequential voting rule aggregates information better than simultaneous voting and is more efficient in some information environments, but sequential voting is inequitable because early voters bear more participation costs.
\end{abstract}

$\mathbf{O}$ n November 7,2000, the polls closed in the eastern time zone portion of Florida at 7:00 p.m. At 7:49:40 p.m., while Florida voters in central time zone counties were still voting, NBC/MSNBC projected that the state was in Al Gore's column. A few seconds later CBS and FOX also declared the state for Gore, and 10 minutes later $\mathrm{ABC}$ projected Florida for Gore, 3 hours before the polls closed in California (Shepard 2001).

Most of the concerns raised after these early election calls were about the problems of inaccuracy (Thompson 2004 is a notable exception). However, even accurate reports of early voting outcomes during an election may mean that the election is fundamentally different from one held where voters participate simultaneously in at least three ways. First, when voters participate sequentially and early results are revealed to later voters, the choices facing the voters are complex as later voters use early voting as a noisy information source and early voters try to anticipate the message their votes can send to later voters and how later voters will react to that message. These choices are even more complicated if voting is a costly act, requiring an

Marco Battaglini is Associate Professor and Alfred P. Sloan Research Fellow, Dept. of Economics, Princeton University, Princeton, New Jersey 08544-1021 (mbattagl@princeton.edu).

Rebecca Morton is Professor, Dept. of Politics, New York University, New York, NY 10012 (rbm5@nyu.edu).

Thomas Palfrey is Flintridge Foundation Professor of Economics and Political Science, Division of Humanities and Social Sciences, 228-77, California Institute of Technology, Pasadena, CA 91125 (trp@hss.caltech.edu).

We thank Anna Bassi, Shivani Nayyar, Valeria Palanza, and Stephanie Wang for their research assistance. We also benefited from the comments of Sandy Gordon, Scott DeMarchi, and participants at the Interactions Workshop at GREQAM, Marseille, the Conference on Constitutional and Scientific Quandries at ICER, Torino, the Conference in Tribute to Jean-Jacques Laffont in Toulouse, the 2005 American Political Science Association Annual Meetings, and seminar participants at the Princeton Center for the Study of Democratic Politics. Rebecca Morton also thanks the Center for support during the early stages of this research. Marco Battaglini acknowledges support from NSF Grant SES-0418150 and SES-0547748 and Thomas Palfrey acknowledges support from NSF Grants SES-0079301 and SES-0094800 and Center for Economic Policy Studies. investment of time and resources, such that some voters may choose to abstain. Second, if voters' behavior does depend on the voting mechanism, then we might expect that sequential and simultaneous voting mechanisms will differ in efficiency. Simultaneous voting can be more informationally efficient than sequential voting if in sequential voting later voters are less inclined to participate or vote to "follow the crowd" rather than their independent judgments. On the other hand, sequential voting might be more economically efficient when voting is costly if the outcome of the voting is equivalent, but fewer voters are required to participate to achieve that outcome. Finally, sequential voting can be inequitable if voters' abstention decisions depend on when they vote, thus the costs of participation are borne unequally by early and late voters. In this paper we address these three concerns about sequential voting-strategic behavior, efficiency, and participation equity - both theoretically and experimentally.

Election reporting of early voters' choices during national elections in the United States is just one example of the many voting situations in which participants choose in a sequential order and individual choices are publicly revealed as they are made. The term roll-call vote refers to the mechanism of calling for individuals' votes as their names are called as listed on a roll and is used in many voting contexts from city council meetings to national legislatures. Voting order is frequently debated in such bodies and in some cases manipulated to affect the outcome or to advantage particular members by changing their voting positions. Another type of controversial sequential voting occurs in U.S. presidential primaries, where voters participate by state and the outcome is the result of the cumulative choices. As discussed in Morton and Williams 2000 many believe that the sequential nature of the primaries gives voters in early states like New Hampshire and Iowa an undue influence on the outcome through their influence on later voters' choices. A similar voting mechanism is used when countries hold sequential referenda over treaties or agreements as in the recent referenda over the proposed European Union Constitution. The order in which countries vote is often argued to have 
an effect on the voting in countries who choose later in the sequence and attempts are made to manipulate that order. Even more significantly, a growing percentage of voters are choosing before election day either by mail or in early voting locations. In Oregon, all elections are conducted by mail over a period of weeks. Over $22 \%$ of the respondents to the National Election Studies post 2004 survey reported voting before election day, with over $73 \%$ of the early voters reporting voting more than a week before election day. Although the information about how early voters choose is assumed to be secret, polls and other surveys are used to estimate these choices making it possible for later voters (or those who mobilize them) to learn how early voters chose prior to making their own choices.

Empirical research on the effect of sequential voting on voter behavior, both experimental and nonexperimental, is surprisingly sparse. Two experimental studies consider sequential voting without abstention: Hung and Plott 2000 and Morton and Williams 1999, 2000. These two studies provide somewhat conflicting conclusions about the extent later voters use early voters' choices to inform their decisions. Hung and Plott investigate sequential voting with a particular concern for the "follow the crowd" behavior. When they included a treatment which induced preference for conformity with monetary incentives, they observe such behavior. Morton and Williams find that in sequential voting later voters do sometimes use the information they infer from earlier voting and that these later voters make more informed choices than in simultaneous voting, supporting concerns about the inequities of sequential voting.

Although roll-call voting in Congress and other legislatures has been extensively studied, we are aware of no studies of such voting that explicitly considers how sequence affects members' decisions. The only nonexperimental empirical research on sequential voting of which we are aware has focused on the effect of early election calls such as in 2000 on later voter turnout (see, e.g., Jackson's [1983] study of the 1980 election). Frankovic (2001) reviews the literature, including several unpublished studies of the 2000 election. Despite the fact that some of the analyses, like Jackson's, find an effect, as Frankovic notes, the studies either use surveys of voters after the election where a number clearly have faulty memories (some respondents claim to have heard network calls earlier than they were actually made) or the studies use aggregate data on past elections to estimate voter preferences in the election studied to infer an effect on voter behavior. She points out rightly the difficulty from drawing conclusions based on the available data. She concludes that "there is little evidence of any impact of calling an election before all the polls are closed." Yet she notes that paradoxically, "there is no doubt that the public perceives this to be a serious problem. While the arguments claiming an effect often are politically motivated, and the research does not support the claim, the public believes otherwise." Is the American public crazy as Frankovic suggests? Or does knowing the results of early voting affect later voters' choices?

\section{THEORETICAL ANALYSIS}

We consider a game with an odd number, $n$, of voters who decide by plurality rule. There are two alternatives $A, B$ and two states of the world: in the first state $A$ is optimal and in the second state $B$ is optimal. Without loss of generality, we label $A$ the first state and $B$ the second. The voters have identical preferences represented by a utility function $u(x, \theta)$ that depends on the state $\theta$ and the action $x: u(A, A)=u(B, B)=v$ and $v(A, B)=v(B, A)=0$, where $v>0$. State $A$ has a prior probability $\pi=\frac{1}{2}$. The true state of the world is unknown, but each voter receives an informative signal. We assume that signals of different agents are conditionally independent and all have the same precision. The signal can take two values $a, b$ with probability: $\operatorname{Pr}(a \mid A)=p=\operatorname{Pr}(b \mid B)$, where $p>\frac{1}{2}$.

Although we assume that voters have identical preferences and thus if fully informed would agree on a common choice, we can think of the voters as having different preferences over policy goals as given by their signals, but at the same time having common ultimate goals as in other models of elections such as CanesWrone, Herron, and Shotts 2001. Battaglini (2005) shows that the distinctions we find between sequential and simultaneous voting also exist when voters have private values.

\section{Costly Voting and Why the Order of Voting Matters}

There is a natural reason why behavior should depend on the order of the voting procedure: when voters can observe previous voters' behavior, they can be influenced by previous choices that may signal private information. In a recent contribution, however, Deckel and Piccione 2000 have questioned this reasoning. They show that, under general conditions, any symmetric equilibrium of the simultaneous voting game in which players use their information is in fact a sequential equilibrium in any sequential voting game and that there always exists equilibrium behavior in the sequential game that is completely independent of the order of voting.

Their argument is based on the observation that a rational voter would realize that he is influential only when pivotal. To see the intuition, assume that voters ignore the sequential order of the voting protocol and behave as if they were in an equilibrium of a simultaneous voting game. In this case, the expected benefit of voting for alternative $A$ for a voter $i$ who votes at stage $t$ after a history $h_{t}$ and an observed signal $s_{i}=a$ can be represented as

$$
\begin{aligned}
U\left(s_{i}\right)= & \operatorname{Pr}\left(P I V_{i} \mid h_{t}, s_{i}=a .\right) \cdot v \\
& \cdot\left[\operatorname{Pr}\left(A \mid P I V_{i}, s_{i}=a .\right)-\frac{1}{2}\right],
\end{aligned}
$$

where $\operatorname{Pr}\left(P I V_{i} ; h_{t}, s_{i}\right)$ is the probability of being pivotal; and $v \cdot \operatorname{Pr}\left(A \mid P I V_{i}, s_{i}\right.$. $)$ is the expected utility obtained if 
$A$ wins conditional on being pivotal and on a signal $s_{i}{ }^{1}$ The probability of being pivotal depends on the signal $s_{i}$ observed by $i$ and on the particular history of votes cast in the previous stages of the game, but the expected utility is independent of $h_{t}$ : in the pivotal event, the agent "knows" how all the others have voted, not only those who choose in the previous stages. The voter decides how to vote on the basis of (1): he votes $A$ when it is positive and votes $B$ when negative. Since $\operatorname{Pr}\left(P I V_{i} \mid h_{t}, s_{i}=a\right) v$ is non-negative, his choice will be determined by the sign of $\left[\operatorname{Pr}\left(A \mid P I V_{i}, s_{i}=a\right)-\frac{1}{2}\right]$, which implies that he finds it optimal to make a choice that is independent of the history. An informational cascade will not occur.

Dekel and Piccione's (2000) result does not imply that the set of symmetric informative equilibria of the simultaneous and sequential voting games are identical, only that the first is a subset of the second. This result leaves open the possibility that the sequential voting game has additional equilibria that are not in the equilibrium set of the simultaneous game. ${ }^{2}$ The importance of Dekel and Piccione lies in the fact that it undermines the ability to conduct meaningful welfare comparisons between alternative voting mechanisms. Is there a reason why we should expect that equilibrium behavior is necessarily different in simultaneous and sequential mechanisms? ${ }^{3}$

An attempt to solve this indeterminacy is provided in Battaglini 2005, by introducing voting costs. When there is a cost of voting $c$ and the agent can abstain, the decision depends on the sign of

$$
\operatorname{Pr}\left(P I V_{i} \mid h_{t}, s_{i}=a\right)\left[v \cdot \operatorname{Pr}\left(A \mid P I V_{i}, s_{i}=a\right)-\frac{1}{2}\right]-c .
$$

In this case the decision is determined by the magnitude of $\operatorname{Pr}\left(P I V_{i} \mid h_{t}, s_{i}\right)$, which depends on $h_{t}$. We should therefore expect to see rates of abstention that depend on the history and that increase as the probability of being pivotal decreases. This strategic abstention phenomenon also suggests that the set of equilibria and the informational properties of the two elections will also differ: the set of equilibria are disjoint and simultaneous voting should be superior when the size of the election is large enough. ${ }^{4}$

\footnotetext{
${ }^{1}$ In particular $v \cdot\left[\operatorname{Pr}\left(A \mid P I V_{i}, s_{i}=a\right)-\frac{1}{2}\right]$ is the net benefit of voting. Assume that if the agent does not vote then there is a tie. If the agent votes he obtains $v$ with probability $\operatorname{Pr}\left(A \mid P I V_{i}, s_{i}=a\right)$ (i.e., the posterior that the state is $\mathrm{A}$ given the fact that he is pivotal and he has observed an a signal), and if he does not vote there is a tie and the policy is correct with probability $\frac{1}{2}$. As it can be easily verified, the case in which if the agent does not vote alternative $B$ wins and if he votes $A$ there is a tie is equivalent.

${ }^{2}$ Indeed, exploiting this fact, Ali and Kartik (2006) have constructed history-dependent equilibria in which voters learn from the behavior of previous voters. See also Fey (1998).

${ }^{3}$ Using a different approach, Gerardi and Yariv (2005) show that a very wide class of voting procedures, including both sequential and simultaneous methods, yield the same set of equilibrium outcomes if voting is preceded by a deliberation stage where the voters can communicate costlessly with one another. This neutrality result does not hold if either deliberation OR voting is costly.

${ }^{4}$ Callander (2004) suggests that the differences between simultaneous and sequential elections can be explained with behavioral
}

In an election this cost straightforwardly represents the cost of the physical time and effort of voting and can also be interpreted as the cost of mobilizing a group of voters to participate. In a legislative situation the cost can be interpreted as the opportunity cost of engaging in other legislative activities-the cost of leaving a meeting of a committee, constituents, or executive officials to cast a ballot in a roll call vote-or even the risk of taking an unpopular stand on an issue. Legislators are often aware of the progress of voting on contested matters while engaging in other activities and can and do choose whether to return to the chamber. The cost could also be interpreted as a cost of position taking if we assume that these costs are independent of the position taken or the outcome of the voting; that is, legislators may see it as desirable to not take any positions on issues. A number of researchers have found evidence that members of Congress, both House and Senate, avoid voting either because of the demands of campaigning or a desire to not to take a policy position (see Thomas 1991; Rothenberg and Sanders 1999, 2000; and Jones 2003). ${ }^{5}$ News accounts complaining of excessive abstention in city councils and other legislative bodies and mandatory rules requiring that members only abstain if they have a conflict of interest also suggest that these members see the act of voting itself as costly.

With costly voting, the net utility function of a voter who votes is therefore $u(x, \theta)-c$ : in state $\theta$ if option $x$ is chosen. We assume that a voter who decides alone would always prefer to pay the cost and determine the outcome of the election: so $c<\frac{1}{2}(2 p-1) v$, where $\frac{1}{2}(2 p-1) v$ is the expected utility of voting for $A(B)$ conditional on a $a(b)$ signal. It is therefore convenient to re-parametrize the cost as $c=\frac{\gamma}{2}(2 p-1)$, where $\gamma \in$ $(0,1)$.

\section{The Voting Games}

We consider two game forms, which we call the simultaneous voting game and the sequential voting game. In both games the outcome is chosen by majority rule and we assume that when $A$ receives the same votes as $B$, or when all voters abstain, then one of the two alternatives is chosen with probability $1 / 2$. In what follows we assume $n=3$. In the simultaneous voting game all voters vote simultaneously. In this case, a (pure) voting strategy for voter $i$ is a map $v_{i}:\{a, b\} \rightarrow\{A, B, \phi\}$ : that is, given the signal, the voter may vote for $A, B$ or abstain. A mixed strategy assigns a probability of abstaining $\sigma_{i}\left(\phi ; s_{i}\right)$, and, conditional on voting a probability of

assumptions on voters. He assumes that voters prefer to vote for winners, so their decision would depend on the voting history. Such a voter would vote for a winning candidate even if he or she is not pivotal.

${ }^{5}$ These studies examine the abstention or position avoidance by members of Congress over a number of bills. Cohen and Noll (1991) present a case study of Congressional abstention on a series of bills on a single issue, and Poole and Rosenthal (1997) analyze aggregate abstention rates as a function of overall legislative ideological preferences. 
voting for each alternative, $\sigma_{i}\left(x ; s_{i}\right), x=A, B$. In the second game form, voters vote sequentially. In this case, a strategy is a function $v_{i}: H_{i} \times\{a, b\} \rightarrow[A, B, \phi]$, where $H_{i}$ is the set of histories that voter $i$ can observe. In this case too we will denote $\sigma_{i}\left(\phi ; s_{i}, h_{i}\right)$ the probability that voter $i$ abstains after observing a signal $s_{i}$ and a history $h_{i}$; and $\sigma_{i}\left(x ; s_{i}, h_{i}\right)$ the respective probability of voting for $x$, conditional on not abstaining.

An equilibrium of the sequential game (resp. simultaneous game) is symmetric if $\sigma_{i}\left(\theta ; s, h_{t}\right)=\sigma_{j}\left(\theta ; s, h_{t}\right)$ for all $i, j$ and all $h_{t} \in H_{t}$, and $\theta \in\{a, b, \phi\}, s \in\{a, b\}$ (resp. if $\sigma_{i}(\theta ; s)=\sigma_{j}(\theta ; s)$ for all $i, j$ and for $\theta \in\{a, b, \phi\}$, $s \in\{a, b\})$. In this symmetric environment there is no a priori difference between state $A$ and state $B$ : it is therefore natural to assume that the names associated with these two states are irrelevant for the strategic considerations of the agents. Let us define $N_{a}\left(h_{t}\right)\left(N_{b}\left(h_{t}\right)\right)$ the number of $a(b)$ votes in a history $h_{t}$; and let $H_{t}^{0}=\left\{h_{t}\right.$ s.t. $\left.N_{a}\left(h_{t}\right)=N_{b}\left(h_{t}\right)\right\}$. After any of these histories the states continue to be symmetric. We define an equilibrium of the sequential game (resp. simultaneous game) to be neutral if two requirements are satisfied: (i) $\sigma_{i}\left(\phi ; a, h_{t}\right)=\sigma_{i}\left(\phi ; b, h_{t}\right)$ for any $h_{t} \in H_{t}^{0}$ (resp. $\left.\sigma_{i}(\phi ; a)=\sigma_{i}(\phi ; b)\right)$; and (ii) $\operatorname{Pr}\left(\theta \mid h_{t}\right)=\operatorname{Pr}\left(\theta \mid h_{t+1}\right)$ for any $h_{t} \in H_{t}^{0}, h_{t+1}=\left\{h_{t}, \phi\right\}$, and $\theta=A, B .{ }^{6}$ Neutrality, therefore requires that if there is no reason imposed by how previous voters have voted to treat the alternatives in a asymmetric way, then their names should be irrelevant for the decision to vote or abstain. In our experiments we find that no significant relationship between voters' choices and the labels of the alternatives. ${ }^{7}$ In the rest of the analysis we focus on symmetric, neutral perfect Bayesian Nash equilibrium in undominated strategies; for simplicity we refer to such an equilibrium as "an equilibrium."

\section{Equilibrium Characterization}

The characterization of equilibria in the simultaneous game is simplified by two observations. First, because we focus on equilibria that are neutral and symmetric and $\pi=0.5$, voters never vote against their signal; they either vote sincerely or abstain. Therefore, to characterize the equilibrium we only need to determine the abstention probabilities, $\left\{\sigma_{i}\left(\phi ; s_{i}\right)\right\}_{i=1}^{3}$. Second, neutrality implies that $\sigma_{i}(\phi ; a)=\sigma_{i}(\phi ; b)=\sigma_{i}(\phi)$, and symmetry implies $\sigma_{i}(\phi)=\sigma_{j}(\phi)=\sigma(\phi)$ for all $i, j$. Therefore we can focus on one variable only: $\sigma(\phi)$, and we drop the dependence on $\phi$, simply writing it as $\sigma$.

The equilibrium value of $\sigma$ is determined by the cost of voting $c$ and the equilibrium expected benefit of voting, which is balanced against the expected utility of not voting, so the usual cost-benefit calculus applies

\footnotetext{
${ }^{6}$ Clearly the second requirement is not implied by the first only out of equilibrium.

${ }^{7}$ It is worth pointing out that non-neutral equilibria exist for some voting costs, but we see no evidence of this kind of behavior in our experiment. Reaching such an equilibrium would require some form of preplay coordination, so that it is common knowledge among all three voters that an abstention by the first voter implies an $a$ signal. Battaglini, Morton, and Palfrey (2005) explicitly construct an example of a non-neutral perfect Bayesian equilibrium.
}

by conditioning on pivotal events. Consider voter $i$ with a signal $s_{i}=a$. His vote is pivotal only in three events. First, when no other voter participates, event $P_{0}$. This event occurs with probability $\sigma^{2}$; and, in this event, the expected benefit of voting for $A$ is equal to $p v$ and the expected benefit of not voting is simply $\frac{1}{2}$. Hence the expected gain from voting in event $P_{0}$ equals $\frac{1}{2}(2 p-1) v$, where $p$ is the posterior probability of state $A$ after one signal $a$. Second, a voter is pivotal when exactly one other player votes, and this player votes $B$, event $P_{1}$. In this case, however, the posterior is $\frac{1}{2}$ because in $P_{1}$ there are exactly two opposite signals that offset on the other, so the expected gain from voting is 0 . The third possibility is when the two other voters vote, and they vote for opposite alternatives, event $P_{2}$. In this case, voter $i$ knows that there are two $a$ signals and one $b$ signal. The posterior is $\operatorname{Pr}\left(A \mid a, P_{2}\right)=\frac{\frac{1}{2} p^{2}(1-p)}{\frac{1}{2} p^{2}(1-p)+\frac{1}{2} p(1-p)^{2}}=p$, and the expected benefit of voting is, again, $\frac{1}{2}(2 p-1) v$. From the point of view of $i$, this event occurs with probability: $\operatorname{Pr}\left(P_{2} \mid a\right)=2(1-\sigma)^{2} p(1-p)$. The expected utility of voting for $A$ for agent $i$ is therefore

$$
\begin{aligned}
u(\text { vote } A \mid a) & \equiv E U(\sigma) \\
& =\frac{1}{2}(2 p-1) v\left[\sigma^{2}+2(1-\sigma)^{2} p(1-p)\right] .
\end{aligned}
$$

Comparing with the cost of voting we have a pure strategy equilibrium in which all agents vote when $E U(0)=$ $(2 p-1) p(1-p) v>c$; and we have a mixed equilibrium at any value of $\sigma \in(0,1)$, such that $E U(\sigma)=c$. Using these conditions we can characterize the set of symmetric equilibria in the simultaneous game.

Proposition 1. In the simultaneous voting game, when $n=3$ :

i. If $c \in\left[0, \frac{p(1-p)(2 p-1)}{1+2 p(1-p)} v\right)$ there is a unique pure strategy equilibrium $\sigma^{*}=0$.

ii. If $c \in\left[\frac{p(1-p)(2 p-1)}{1+2 p(1-p)} v, p(1-p)(2 p-1) v\right]$ there are three equilibria: one pure strategy equilibrium $\sigma^{*}=0$, and two mixed strategy equilibria.

iii. If $c \in\left(p(1-p)(2 p-1) v, \frac{1}{2}(2 p-1) v\right)$, there is a unique mixed strategy equilibrium $\sigma^{*} \in(0,1)$

In the sequential game the action of an agent affects the outcome in two ways. First, we have a direct effect: given the vote of the others, a vote in favor of an option increases its plurality. But the vote of early voters has an indirect influence on later voters as well: the vote signals the voter's information to the remaining voters. This allows information to be leaked in a way that is not possible with simultaneous voting, and this leakage may lead to efficiency gains because later voters will rationally (and efficiently) abstain after some sequences of decisions by earlier voters. We focus on sincere equilibria in which no voter votes against his own signals. Although there can exist equilibria where early voters vote against their signals, they are intuitively 
implausible, inefficient, and not observed in our experiments. ${ }^{8}$ At least one sincere equilibrium always exists, and it is unique in the three-voter case we are considering here. The following proposition summarizes the unique path of equilibrium play as a function of the voting cost and informativeness of the signal. ${ }^{9}$

Proposition 2. In the sequential voting game, when $n=3$ there exists a unique sincere, neutral equilibrium path, for all voting costs, and this equilibrium is in pure strategies. The equilibrium path is as follows:

i. If $c \in[0, p(1-p) 2 p-1) v]$, the first voter votes (sincerely), the second voter votes only if the first voter has voted and he has a different signal than the first voter; and the last voter only if the first and second voters vote for opposite alternatives or if no voter votes before. All voters vote informatively when they vote;

ii. If $c \in\left[p(1-p)(2 p-1) v, \frac{1}{2}(2 p-1) v\right]$, the first and second voters abstain and the third voter votes (sincerely).

\section{Theoretical Implications for Efficiency and Equity}

Propositions 1 and 2 present a clear characterization of the equilibria. When $c<\frac{p(1-p)(2 p-1) v}{1+2 p(1-p)}$ and $c>p(1-p)$ $(2 p-1) v$, we have a unique equilibrium in both the simultaneous and in the sequential models, and these equilibria are different. In particular:

- When $c<\frac{p(1-p)(2 p-1) v}{1+2 p(1-p)}$ there is a unique equilibrium of the simultaneous game in which the voters vote informatively and never abstain. In the sequential game there is a unique equilibrium in pure strategies as described in point $i$ of Proposition 2.

- When $c>p(1-p)(2 p-1) v$, there is a unique equilibrium of the simultaneous game in which the voters abstain with probability $E U^{-1}(c) \in(0,1)$ and vote informatively with the complementary probability. In the sequential game there is a unique equilibrium in pure strategies in which only the last voter votes in equilibrium, as described in point $i i$ of Proposition 2.

In the rest of the paper we focus on parameters only in these two regions to avoid multiplicity of equilibria. We refer to the first case as the low-cost case and to the second case as the high-cost case. Given this, we should expect very different behavior between simultaneous and sequential elections, and given the voting mechanism between low and high costs. In particular:

- In simultaneous elections, we should expect the probability of abstention to be decreasing in the cost

\footnotetext{
${ }^{8}$ Battaglini, Morton, and Palfrey (2005) show with an example that insincere equilibria may exist.

${ }^{9}$ Off the equilibrium path behavior is more complicated and we present our predictions for these situations in the context of our experiments in Table 3.
}

of voting: the probability should be zero in the lowcost region and positive in the high-cost region.

- In sequential elections with low costs, the first voter should always vote and late voters should vote only if they find it optimal to correct the choice of earlier voters and if they are pivotal. In sequential elections with high costs the opposite should occur-they should be characterized by free riding from early voters who should abstain counting on the participation of late votes.

These differences have an impact on the theoretical efficiency and equity properties of the voting mechanisms as well as noted above. With respect to equity, in a symmetric equilibrium under simultaneous voting all voters obtain the same expected utility, in the sequential mechanism expected utility depends on the stage in which the agent votes. When the cost is low and the later voters free ride, early voters receive a lower utility level than later voters; in a high-cost regime, on the contrary, early voters free ride on the participation of later voters and obtain higher expected utility. The predictions with respect to efficiency will be discussed in greater details where we develop the appropriate benchmark case for efficiency: here we note that when the cost is low we should expect lower abstention than with high voting costs: therefore, we should expect a more efficient collective choice when the cost of voting is low.

\section{EXPERIMENTAL DESIGN}

The experiments were conducted at the Princeton Laboratory for Experimental Social Science and subjects were registered students at Princeton University. All the laboratory experiments used $p=0.75$ and $v=40$ cents. We used two different treatments for the cost of voting: $c=8$ cents and $c=2$ cents. These parameters were selected such that under each voting mechanism there are unique equilibrium predictions; thus we have distinctive predictions about voter behavior, efficiency, and equity. Six sessions were conducted, each with either 9 or 12 subjects. ${ }^{10}$ Each subject participated in exactly one session. Each session was divided into two half-sessions with different treatments, each of which lasted for 20 rounds for a total of 40 rounds per session. Table 1 summarizes the session predictions according to the cost parameters.

Subjects were randomly divided into groups of three for each round and in the sequential voting treatments were randomly assigned voting positions (first, second, or third voter) within each new group. Instructions were read aloud and subjects were required to correctly answer all questions on a short comprehension quiz before the experiment was conducted. Subjects were also provided a summary sheet about the experiment which they could consult. The experiments were conducted

\footnotetext{
${ }^{10}$ Each session included one additional subject who was paid $\$ 20$ to serve as a monitor.
} 
TABLE 1. Experimental Design

\begin{tabular}{lllc}
\hline Session & \multicolumn{1}{c}{ First 20 rounds } & Second 20 rounds & No. of Subjects \\
\hline 1 & High-cost simultaneous & Low-cost sequential & 9 \\
2 & Low-cost simultaneous & High-cost sequential & 12 \\
3 & Low-cost sequential & High-cost simultaneous & 12 \\
4 & High-cost sequential & Low-cost simultaneous & 12 \\
5 & High-cost sequential & Low-cost sequential & 12 \\
6 & Low-cost sequential & High-cost sequential & 12 \\
\hline
\end{tabular}

\begin{tabular}{|c|c|c|c|c|c|c|c|c|}
\hline & \multicolumn{4}{|c|}{ Low Cost } & \multicolumn{4}{|c|}{ High Cost } \\
\hline & Data & Nash & QRE1 ${ }^{a}$ & QRE2 & Data & Nash & QRE1 & QRE2 \\
\hline Abstained & 0.39 & 0 & 0.39 & 0.42 & 0.68 & 0.89 & 0.68 & 0.70 \\
\hline Voted signal & 0.58 & 1 & 0.61 & 0.58 & 0.31 & 0.11 & 0.32 & 0.30 \\
\hline Voted contrary & 0.029 & 0 & 0 & 0 & 0.007 & 0 & 0 & 0 \\
\hline & & & 0.49 & 0.30 & & & 0.25 & 0.30 \\
\hline Log likelihood & & & 320.91 & 586.1 & & & 263.74 & 586.1 \\
\hline Total obs. & 480 & & & & 420 & & & \\
\hline
\end{tabular}

via computers. ${ }^{11}$ Subjects were told there were two possible jars: Jar 1 and Jar 2. Jar 1 contained six red balls and two blue; jar 2 contained six blue balls and two red. For each group, one of the jars was randomly selected by the computer, with replacement. The balls were then shuffled in random order on each subject's computer screen, with the ball colors hidden. Each subject then privately selected one ball by clicking on it with her mouse and thereby revealing its color to that subject only. The subject then chose whether to vote for Jar 1, Jar 2, or abstain. If the majority of the votes cast by a group were for the correct jar, each group member, regardless of whether she voted, received a payoff of 50 cents (minus the cost of voting if she voted). If the majority of the votes cast by a group were incorrect guesses, each group member, regardless of whether she voted received a payoff of 10 cents (minus the cost of voting if she voted). Ties were broken randomly. This was repeated in the next round, with group membership shuffled randomly between each round. Each subject was paid the sum of her earnings over all rounds in cash at the end of the session. Average earnings were approximately $\$ 25$, with each session lasting about 90 minutes.

\section{EXPERIMENTAL RESULTS}

\section{Individual Choices: Does Sequence Matter?}

Simultaneous Voting Choices. Our theoretical analysis of simultaneous voting suggests that we should see zero abstention in the low-cost treatment and positive abstention in the high-cost treatment. Table 2 summarizes the voting choices of participants in the

\footnotetext{
11 The computer program used was similar to that of Guarnaschelli et al. (2000) for jury decision making experiments without abstention, rewritten as an extension to the open source Multistage game software. See http://multistage.ssel.caltech.edu.
}

simultaneous voting games. Of the 900 individual voting decisions in the simultaneous voting games, only $17(<2 \%)$ were votes against a subject's signal, and of these 11 were cast by two subjects in the low-cost treatment. Abstention was significantly higher in the high cost treatment than in the low cost games $(67.86 \%$ compared to $38.96 \%$ ). As is clear from Table 2, we find little support for the exact quantitative Nash equilibrium predictions in simultaneous voting: low-cost voters abstain significantly more than predicted, and highcost voters abstain significantly less than predicted. ${ }^{12}$ However, the Nash solution assumes voters behave perfectly rationally with no error. Given the complexity of the game they are playing, such a strong assumption seems implausible.

An alternative approach, following McKelvey and Palfrey 1995, 1998, is to consider a statistical version of Nash equilibrium where, for each actor, all possible actions have a positive probability with the probabilities ordered by the expected payoffs of the actions. The specification of these probabilities uses a quantal response function, which is a statistical version of a best response function. Of course, these "quantal" responses will also be influenced by the probability distribution of choices by the other players in the game and so on. A QRE is the fixed point of this iterative process, just as Nash equilibrium is a fixed point of the best response iteration. To simplify computations, we consider QRE of only the simplified version of the simultaneous voting game in which players choose either to vote sincerely or to abstain. The conclusions

\footnotetext{
12 We also estimated a multinomial probit to determine if there were learning effects where we find significant evidence that voters increase the probability of abstaining in the high-cost treatment but little evidence of learning in the low-cost case. We performed similar estimations for voters in the sequential treatments and found limited evidence of learning.
} 


\section{FIGURE 1. Simultaneous Voters' QRE Abstention Probabilities}

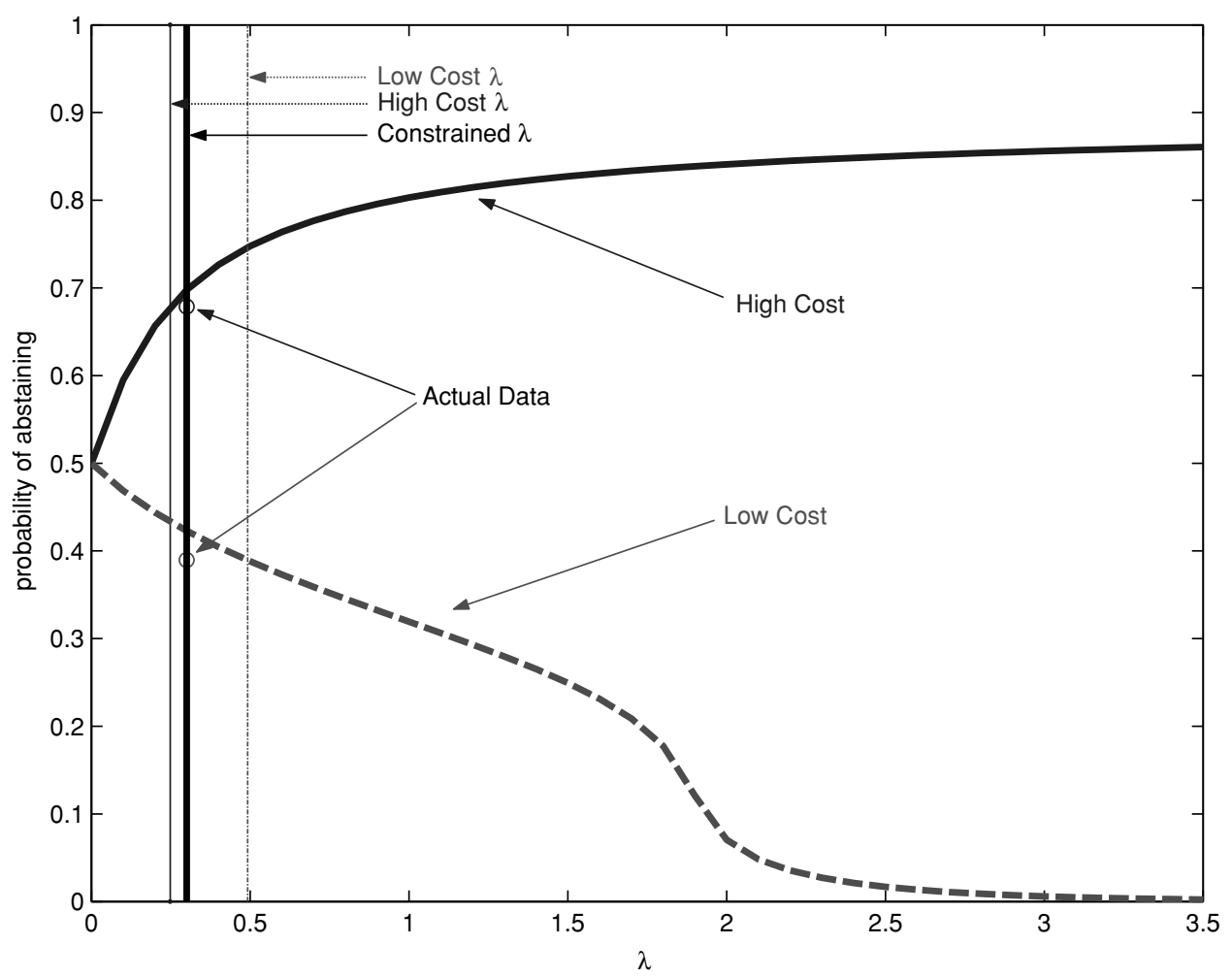

are unchanged if we use a QRE model where subjects vote against their signal with some probability. To provide parametric estimates in our analysis, we use the logit specification of QRE, where the quantal response functions are logit curves and $\lambda$ is the response parameter. When $\lambda=0$, the response curves are flat and all strategies are used with equal probability, or zero rationality. As $\lambda$ approaches $\infty$, the logit response curves converge to the best response curves, or perfect rationality. Thus, the Nash equilibrium predictions correspond to a boundary case of the QRE model.

Our estimates of the QRE for the simultaneous voting games are given in Table 2 . We estimated three values of $\lambda$, one where $\lambda$ is constrained to be equal across cost treatments (corresponding predicted abstention rates are given in columns 5 and 9) and two unconstrained values of $\lambda$ by cost treatment, $\lambda_{H}$ and $\lambda_{L}$ for high- and low-cost treatments, respectively. For all rounds, using a likelihood ratio test, the difference between $\lambda_{H}$ and $\lambda_{L}$ is not significant at the $5 \%$ level (the $\chi^{2}$ equals 2.9). This finding suggests that a unique parameter can explain behavior of the subjects in the simultaneous game, even though the Nash equilibria are extremely different in the high- and low-cost treatments. We find little change in the values of $\lambda_{H}$ and $\lambda_{L}$ over time, except for some apparent convergence toward each other (and to the constrained value). For the last 10 rounds we find the difference not significant at any conventional level (the $\chi^{2}$ equals 1.2 ).

Figure 1 presents the relationship between the probability of abstaining and the equilibrium values of $\lambda$ for both the low- and high-cost treatments along with the estimated values for our treatments. The two curves show the equilibrium abstention rates for each cost treatment associated with given values of $\lambda$. For $\lambda=0$, the QRE predicted abstention rates for both low- and high-cost treatments is equal 0.5. As $\lambda$ increases, the equilibritum abstention rate in the low-cost treatment approaches zero, whereas the equilibrium abstention rate in the high-cost treatment approaches the Nash equilibrium prediction of 0.89 . The vertical lines denote the values of $\lambda$ for both the constrained and unconstrained estimations and the small circles the observed abstention rates in the treatments.

\section{Sequential Voting Choices}

In the sequential voting games theory implies two types of strategic abstention: in the low-cost treatment, the equilibrium predicts that later voters will strategically abstain when they are not pivotal, voting sincerely otherwise and in the high-cost treatment, the equilibrium predicts that early voters will strategically abstain, leaving the choice for later voters. If early voters do vote, later voters will choose sincerely if pivotal, otherwise they will strategically abstain. Table 3 summarizes the aggregate abstention rates at all information sets as well as our predictions for both equilibrium and off the path behavior. We pool observations for voters with $a$ and $b$ signals. In the history column, "S" indicates that a previous voter voted for the alternative 


\begin{tabular}{|c|c|c|c|c|c|c|c|c|c|}
\hline \multirow[b]{2}{*}{ Voter } & \multirow[b]{2}{*}{ History* } & \multicolumn{4}{|c|}{ Low Cost } & \multicolumn{4}{|c|}{ High Cost } \\
\hline & & Data & Nash & QRE & \# Obs & Data & Nash & QRE & \# Obs \\
\hline$\overline{1}$ & & .33 & 0 & .46 & 300 & .45 & 1 & .63 & 320 \\
\hline 2 & A & .39 & 1 & .51 & 100 & .50 & 1 & .61 & 144 \\
\hline 2 & $\mathrm{~s}$ & .71 & 1 & .55 & 129 & .84 & 1 & .70 & 108 \\
\hline 2 & D & .41 & 0 & .29 & 71 & .68 & 0 & .68 & 68 \\
\hline 3 & $A, A$ & .32 & 0 & .19 & 39 & .33 & 0 & .44 & 72 \\
\hline 3 & $A, S$ & .80 & 1 & .59 & 60 & .79 & 1 & .72 & 72 \\
\hline 3 & $A, D$ & .63 & 1 & .59 & 27 & .63 & 1 & .72 & 35 \\
\hline 3 & $S, A$ & .99 & 1 & .59 & 79 & .93 & 1 & .72 & 82 \\
\hline 3 & $\mathrm{D}, \mathrm{A}$ & .69 & 1 & .72 & 42 & .71 & 1 & .74 & 55 \\
\hline 3 & S, S & 1.00 & 1 & .59 & 23 & .88 & 1 & .72 & 8 \\
\hline 3 & $\mathrm{D}, \mathrm{D}$ & .92 & 1 & .59 & 13 & 1.00 & 1 & .72 & 7 \\
\hline 3 & $S, D$ & .22 & 0 & .19 & 18 & .33 & 0 & .44 & 15 \\
\hline \multirow[t]{2}{*}{3} & $D, S$ & .32 & 0 & & & .56 & 0 & .44 & 9 \\
\hline & & \multicolumn{2}{|c|}{ All periods } & \multicolumn{2}{|c|}{ Periods $11-20$} & \multicolumn{2}{|c|}{ All Periods } & \multicolumn{2}{|c|}{ Periods $11-20$} \\
\hline \multicolumn{2}{|c|}{ Lambda } & \multicolumn{2}{|c|}{0.19} & \multicolumn{2}{|c|}{0.16} & \multicolumn{2}{|c|}{0.13} & \multirow{2}{*}{\multicolumn{2}{|c|}{$\begin{array}{r}0.16 \\
-286\end{array}$}} \\
\hline \multirow{2}{*}{\multicolumn{2}{|c|}{$\begin{array}{l}\text { Log likelihood } \\
\text { Pooled estimation }\end{array}$}} & & & \multicolumn{2}{|c|}{-291.73} & \multicolumn{2}{|c|}{-593.15} & & \\
\hline & & \multicolumn{4}{|c|}{ All periods } & \multicolumn{4}{|c|}{ Periods $11-20$} \\
\hline \multicolumn{2}{|c|}{ Constrained Lambda } & & \multicolumn{4}{|c|}{0.16} \\
\hline \multicolumn{2}{|c|}{ Const. log likelihood } & \multicolumn{5}{|c|}{$\begin{array}{l}-1178.00 \\
{ }^{\star} \text { Examples of History Notation }\end{array}$} & \multicolumn{2}{|c|}{-578.63} & \\
\hline A & \multirow{2}{*}{\multicolumn{9}{|c|}{$\begin{array}{l}\text { Abstained } \\
\text { First voter voted same as second voter's signal }\end{array}$}} \\
\hline $\mathrm{S}$ & & & & & & & & & \\
\hline & \multirow{2}{*}{\multicolumn{9}{|c|}{$\begin{array}{l}\text { First voter voted differently from second voter's signal } \\
\text { First voter abstained, second voter voted third voter's signal (etc.) }\end{array}$}} \\
\hline A, S & & & & & & & & & \\
\hline
\end{tabular}

consistent with the current voter's signal (i.e., the same as the current voter's signal), and " $D$ " indicates that a previous voter voted for the alternative inconsistent with the current voter's signal (i.e., different from the current voter's signal). "A" represents abstention by a previous voter. For the histories facing the third voter, the first character refers to the voting choice of the first voter with respect to the third voter's signal, and the second character refers to the voting choice of the second voter with respect to the third voter's signal. Out of 1,860 voting decisions, we observed only $27(<1.5 \%)$ cases where voters voted against their signal, and these were scattered randomly across the information sets. We discuss the results of the table in the reverse order of voting.

Third Voters' Choices. As with simultaneous voters, only 4 out of $620(0.6 \%)$ voting choices were contrary to third voters' signals. Thus we find essentially no evidence of "follow-the-crowd" behavior or information cascades, even when third voters are not pivotal. Rational third voters will strategically abstain if their votes are not pivotal. Third voters are significantly more likely to abstain when it is clear that their vote is irrelevant in both the high- and the low-cost treatments-in 270 of the 283 cases $(95.4 \%$ ), where voting their signal would not have altered the outcome, third voters abstained. Theory performs less well in predicting voter choices in situations where their votes are pivotal and we would expect third voters to vote. That is, when both voters 1 and 2 abstain, third voters vote only in 75 out of 111 cases $(67.57 \%)$ and when voters 1 and 2 votes conflict, third voters vote only in 22 of 67 cases $(32.84 \%)$.

Second Voters' Choices. The Nash equilibrium makes the following predictions about second-voter behavior: in both the low- and high-cost treatments, we predict second voters to strategically abstain if first voters voted their signals or if first voters abstained, and to vote sincerely if first voters voted contrary to their signals. The decisions of the second voter are displayed in Table 3, broken down by the decision of the first voter and the signal of the second voter. As discussed previously, we find few voters voting contrary to their own signals, 10 out of 620 voting choices $(1.6 \%)$. In the lowcost treatment, second voters abstain significantly more than simultaneous voters ( $t$ statistic of 3.94) and first voters $(\mathrm{t}$ statistic $=5.04)$. In the high-cost treatment, there is no significant difference between simultaneous voters' abstention choices and second voters' ( $t$ statistic $=0.73$ ), but second voters do abstain significantly more than first voters $(\mathrm{t}$ statistic $=5.27)$. These results reflect the fact that we find strong evidence of strategic abstention when first voters vote second voter's signals. When first voters abstain, however, second voters in the low-cost treatment are more likely to vote than abstain, whereas second voters in the high-cost treatment are equally likelly to vote or abstain. When first voters vote contrary to the second voter's signal, low-cost voters are more likely to vote than abstain, while high cost voters are more likely to abstain than vote.

First Voters' Choices. The Nash equilibrium predicts that first voters will choose sincerely in the low-cost 


\section{FIGURE 2a. First Voter's QRE Abstention Probabilities}

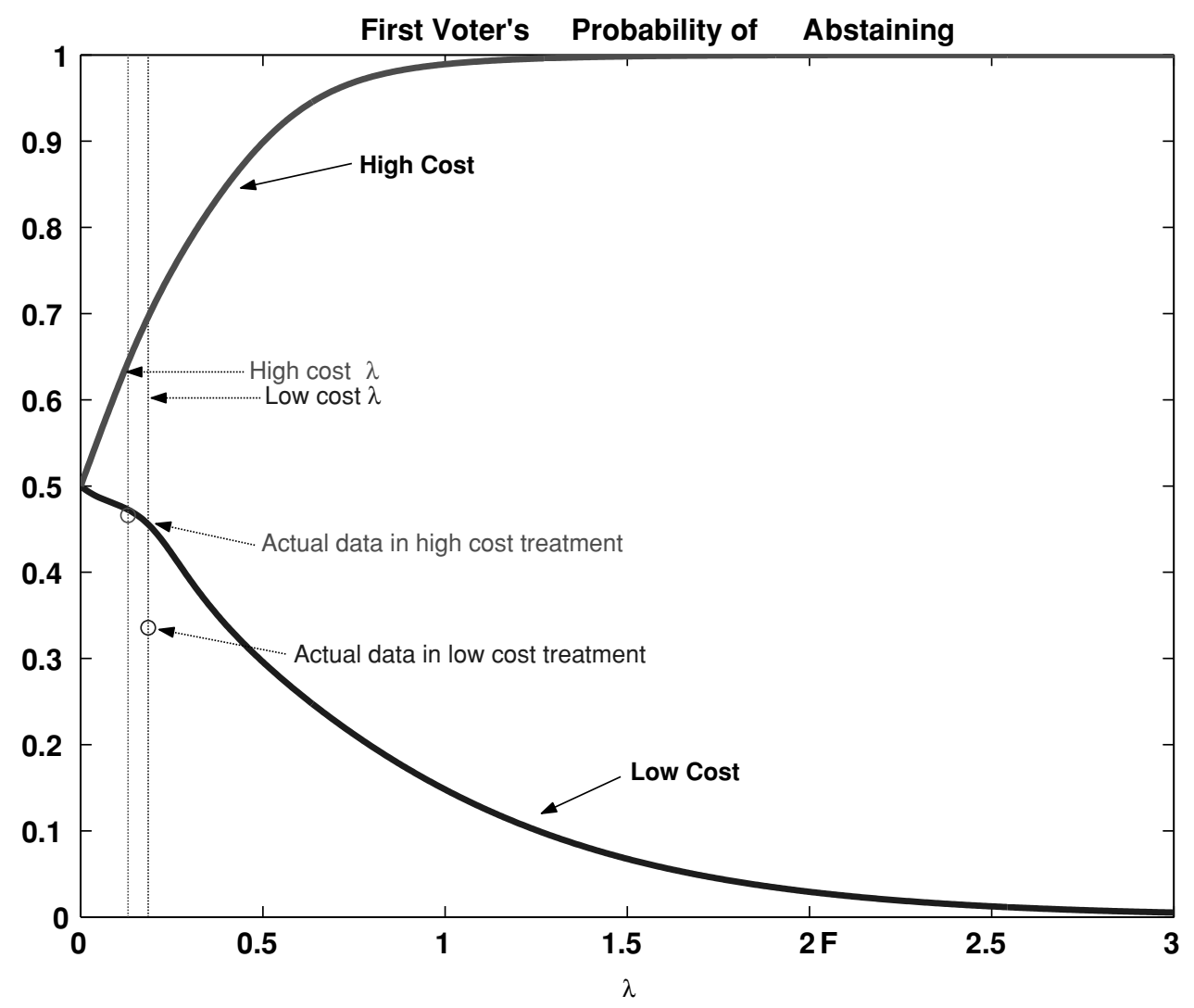

treatment and abstain in the high-cost treatment. As earlier, few first voters voted contrary to their signal, only 13 out of 620 voting choices $(2.1 \%)$. Also as with the voters in the simultaneous voting games, first voters abstained significantly more in the high-cost treatment than in the low-cost treatment ( $\mathrm{t}$ statistic $=$ 2.99). However, first voters in the sequential voting games are significantly less likely to abstain than voters in the simultaneous game with the same cost treatment, and this difference is highly significant in the high cost treatment (low-cost t statistic $=1.6$ and highcost $\mathrm{t}$ statistic $=6.35)$. Thus, whereas cost increases abstention, as predicted, first voters in the high-cost treatment abstain far less than theoretically predicted. Suprisingly few first voters strategically abstain in the high-cost sessions (i.e., pass the choice on to later voters).

QRE Estimation. As with the simultaneous voting game, we estimate the QRE for the simplified sequential voting game (where voters either vote their signals or abstain); the results from that estimation is also presented in Table 3. We did not estimate the QRE model where voters could vote against their signal, due to computational limitations. As in the QRE estimation of the simultaneous game, the assumption is that voters use a logit response function and we solve for the QRE fixed point of the sequential game. As earlier, $\lambda$ is our measure of voter responsiveness, where higher values of $\lambda$ corresponding to behavior that is more consistent with perfect best responses. We report the estimate where $\lambda$ is constrained to be the same for both lowand high-cost sessions as in the simultaneous voting game analysis, and also report the separate estimates. Figures $2 \mathrm{a}, 2 \mathrm{~b}$, and $2 \mathrm{c}$ display the logit equilibrium correspondences for the sequential game for both low and high cost treatments with unconstrained values of $\lambda .{ }^{13}$ Figure 2 a displays the correspondences for the first voter; Figure $2 b$, for the second voter; and Figure $2 c$, for the fhird voter. Note that in Figures $2 b$ and $2 c$, the equilibrium correspondences depend on the voter's information set with the histories defined as in Table 3 described earlier.

As in the simultaneous voting analysis, we find a lack of significant difference between $\lambda_{H}$ and $\lambda_{L}$, and an apparent convergence over time. For all rounds the likelihood ratio test the $\chi^{2}$ statistic equals 4.88 which is barely significant, but for the last 10 rounds the $\chi^{2}$ statistic is less than 0.01. As with the simultaneous game, this fact suggests that a single value of the QRE parameter, $\lambda$, can explain behavior in quite different strategic environments. That is, just one parameter explains behavior at different nodes of the game in which

\footnotetext{
${ }^{13}$ The constrained $\lambda$ lies between the two and is not shown on the figures.
} 


\section{FIGURE 2b. Second Voter's QRE Abstention Probabilities}
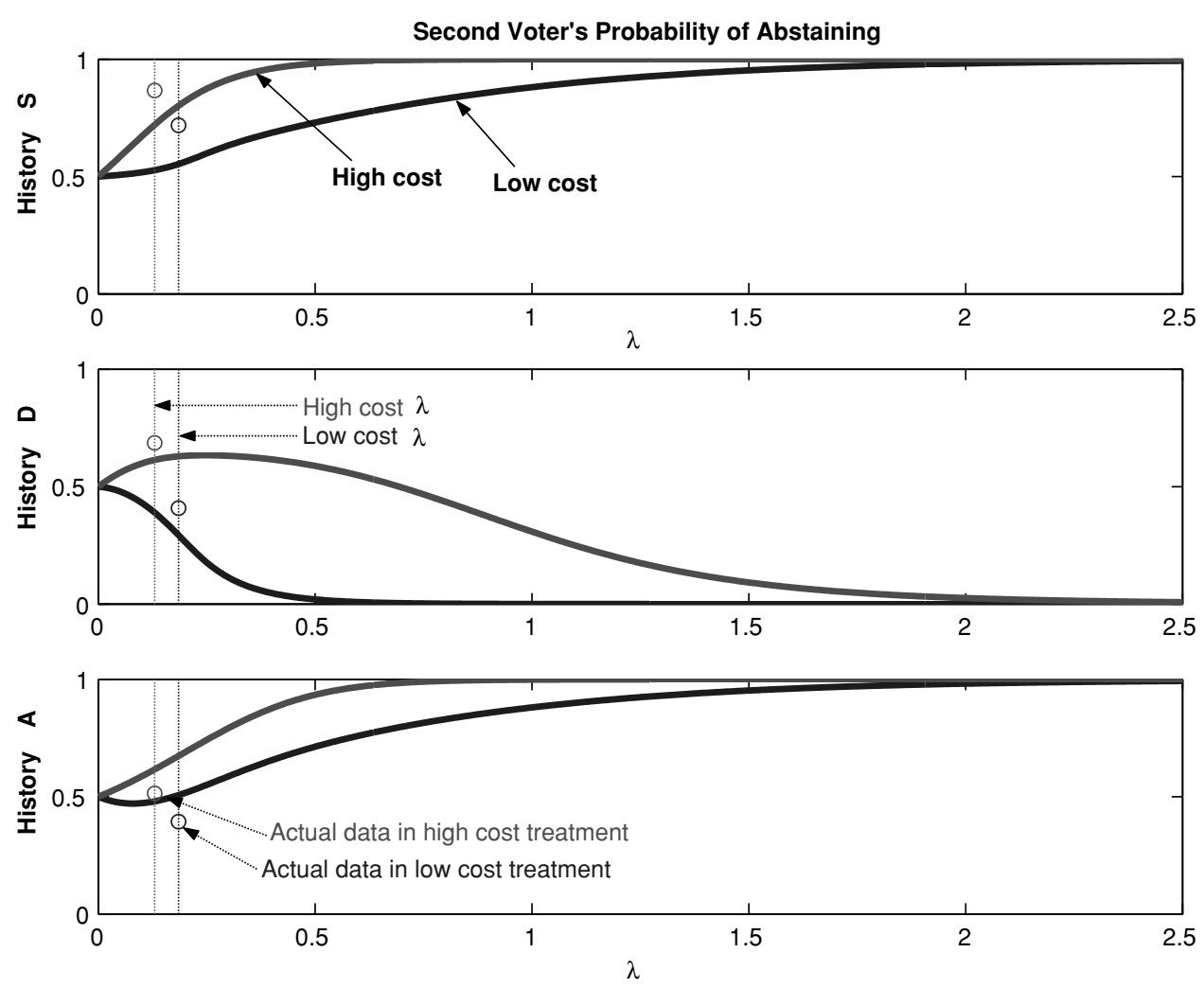

Note: History $\mathrm{S}=$ first voter voted same as second voter's signal; $\mathrm{D}=$ first voter voted differently from voter's signal; $\mathrm{A}=$ first voter abstaines.

subjects are in different stages of voting and information sets.

We also estimated a constrained value of $\lambda$ for all the data (simultaneous and sequential, low and high cost). Because we had more observations of sequential voting for a greater number of information sets, the resulting $\lambda$ was almost identical to the constrained $\lambda$ for the sequential voting games, that is 0.155 . A likelihood ratio test shows that the estimates for the sequential and simultaneous games are significantly different. This is not surprising, because the simultaneous and sequential game forms are completely different. The sequential game form has many different information sets and is a signaling game, which requires players to make subtle inferences from earlier player's choices. This has been observed elsewhere, even when comparing two simultaneous-move games. ${ }^{14}$

Besides providing a much better quantitative fit to the data than the Nash equilibrium, the QRE model also makes a number of successful qualitative predictions about treatment effects, where Nash equilibrium predicts no effect at all. For the second and third voters, for any value of $\lambda$, the QRE abstention probabilities are higher in the high-cost treatment than the low-cost treatment.

\footnotetext{
${ }^{14}$ See, for example, Camerer, Palfrey, and Rogers 2006. How to endogenize $\lambda$ and to characterize how it varies across games are interesting and challenging open theoretical questions.
}

Furthermore, Nash equilibrium predicts no effect at any history for the second and third voters, whereas QRE predicts such effects, independent of the value of $\lambda$. This is borne out in the data too, for the most part. For all three histories, the second voter abstains more often in the high-cost treatment ( $\mathrm{t}$ statistic $=$ 3.05). In fact, for the high-cost treatment, after a contradictory vote by the first voter, the second voter chooses to abstain more often than voting, which is consistent with QRE, but grossly inconsistent with the Nash prediction of always voting. The reason is that, given the actual behavior by the third voter, the second voter is actually better off abstaining than voting in that history (contrary to Nash equilibrium). For the third voter, the positive cost effect on abstention conditional on history is generally not significant, but goes in the direction predicted by QRE in 5 out of 9 histories. These directional predictions are independent of $\lambda$.

As the previous analysis shows, we can conclude the following about strategic abstention:

1. We find weak evidence of strategic abstention by early voters. First voters do abstain more under the high-cost treatment, passing the choice on to later voters, but abstain less than simultaneous voters facing the same cost. First voters respond significantly to expected utility gains from voting. 


\section{FIGURE 2c. Third Voter's QRE Abstention Probabilities}
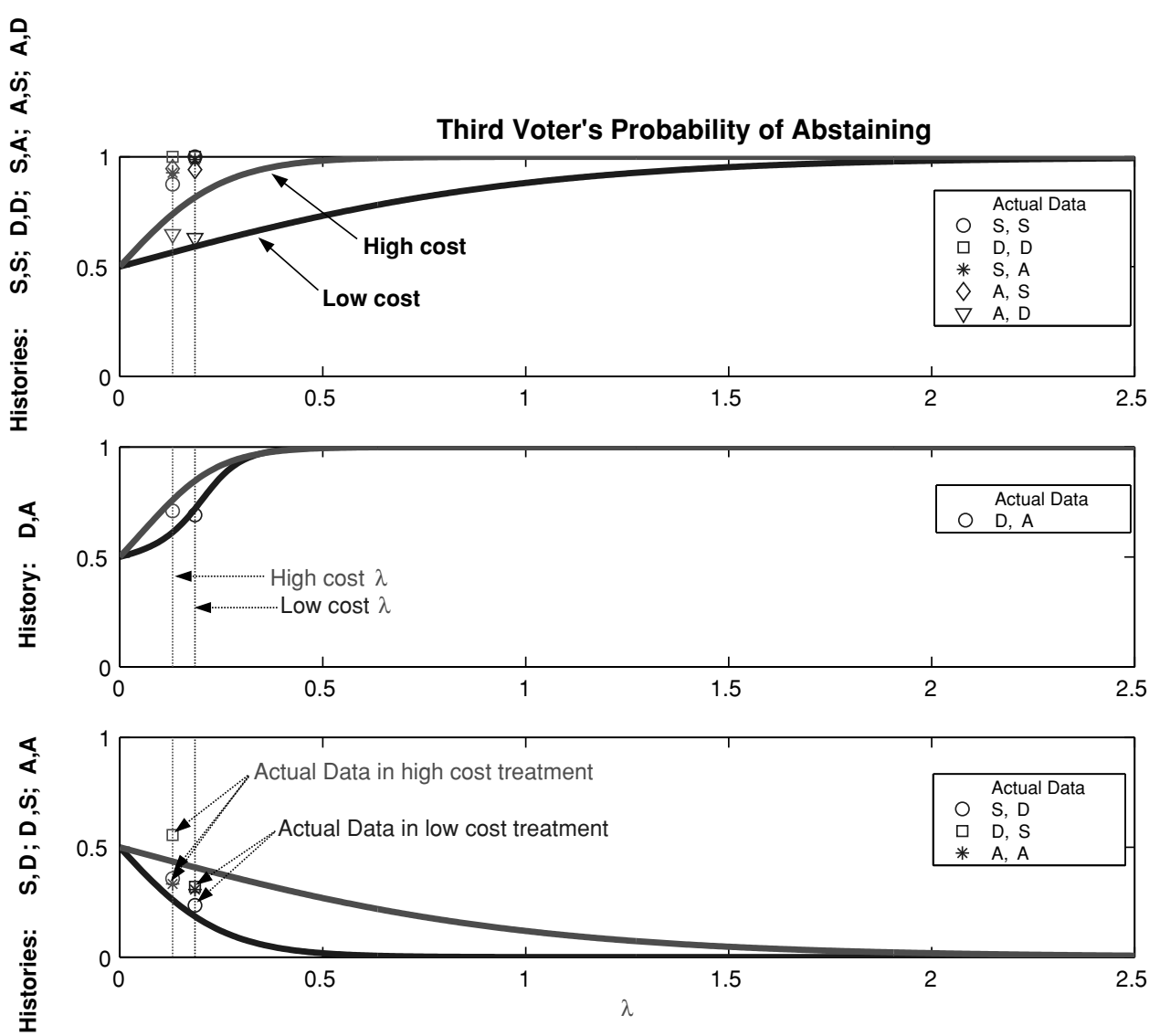

Note: History S, D refers to case where first voter voted same as third voter's signal and second voter voted differently from third voter's signal; other cases similarly interpreted; $\mathrm{A}=$ abstention.

2. We find strong evidence of strategic abstention by later (third) voters when they are not pivotal and second voters "passing" on voting when first voters' choices agree with their signals.

\section{EFFICIENCY OF THE VOTING MECHANISMS}

\section{Informational Efficiency: How Accurate are Decisions?}

As noted in the introduction, we distinguish two different kinds of efficiency: informational and economic. First we consider the informational efficiency of the simultaneous and sequential voting games. Informational efficiency is simply defined as decision accuracy, without consideration for the deadweight loss of voting costs. What fraction of the time does the committee make the right decision?

To answer this question and allow comparison with a benchmark, we construct two indices of accuracy. The "optimal" voting mechanism from the standpoint of informational efficiency is a full information mechanism, where all voters always vote their signal. For the parameters of our experiment, the best the committee can do on average is to vote correctly with ex ante probability $\frac{27}{32}=.84$. Conditional on the actual signal draws, the best possible decision accuracies are $(.96, .75)$ depending on whether three or two of the committee member's signals agreed with each other, respectively. Using this as a benchmark, we compute an empirical measure of decision accuracy $(D A)$ for each treatment and each combination of signals for both the predicted Nash equilibrium strategies and the actual strategies used in the experiment. $D A$ is the fraction of actual decisions that match the decision that would have been made in the full information mechanism, given the committee members' actual signal draws. ${ }^{15}$

Table 4 presents comparisons of informational efficiency across treatments according to whether voting is sequential or simultaneous, by computing the difference in scores $(\Delta \mathbf{D A})$. In the Nash equilibrium, decision accuracy should depend on both costs and the voting mechanism. When we hold the voting mechanism constant, we expect that an increase in cost should decrease informational efficiency except when three signals agree and voting is sequential. Not surprisingly,

\footnotetext{
15 The choice of a benchmark does not affect our results. Other benchmarks yield similar conclusions.
} 


\begin{tabular}{|c|c|c|c|c|c|}
\hline \multicolumn{6}{|c|}{ Informational Efficiency-Comparisons of $\triangle \mathrm{DA}$} \\
\hline Cases & Comparison & Nash & Data & $\mathbf{p}$ & $\mathbf{q}_{\mathrm{FDR}}$ \\
\hline All Cases & $\begin{array}{l}\text { Low seq.> Low sim. } \\
\text { High seq. }>\text { High sim. }\end{array}$ & $\begin{array}{l}.003 \\
.16\end{array}$ & $\begin{array}{l}.05 \\
.05\end{array}$ & $\begin{array}{l}0.05 \\
0.08\end{array}$ & $\begin{array}{l}0.034 \\
0.04\end{array}$ \\
\hline 3 Sigs. agree & $\begin{array}{l}\text { Low seq. }>\text { Low sim. } \\
\text { High seq. }>\text { High sim. }\end{array}$ & 0 & $\begin{array}{l}.05^{*} \\
.09^{*}\end{array}$ & $\begin{array}{l}0.02 \\
0.01\end{array}$ & $\begin{array}{l}0.03 \\
0.03\end{array}$ \\
\hline 2 Sigs. agree & $\begin{array}{l}\text { Low seq. }>\text { Low sim. } \\
\text { High seq. }>\text { High sim. }\end{array}$ & $\begin{array}{l}0 \\
.04\end{array}$ & $\begin{array}{l}.05 \\
.02\end{array}$ & $\begin{array}{l}0.14 \\
0.31\end{array}$ & $\begin{array}{l}0.05 \\
0.05\end{array}$ \\
\hline \multicolumn{6}{|c|}{ Economic Efficiency—Comparisons of Net Exp. Ben. Differences } \\
\hline All Cases & $\begin{array}{l}\text { Low seq. }>\text { Low sim. } \\
\text { High seq. }>\text { High sim. }\end{array}$ & $\begin{array}{l}-2.35 \\
18.24\end{array}$ & $\begin{array}{l}5.76^{*} \\
3.43\end{array}$ & $\begin{array}{l}0.02 \\
0.12\end{array}$ & $\begin{array}{l}0.04 \\
0.05\end{array}$ \\
\hline 3 Sigs. agree & $\begin{array}{l}\text { Low seq. }>\text { Low sim. } \\
\text { High seq. }>\text { High sim. }\end{array}$ & $\begin{array}{c}4 \\
43.28\end{array}$ & $\begin{array}{l}6.79^{* *} \\
9.63^{* *}\end{array}$ & $\begin{array}{l}0.01 \\
0.01\end{array}$ & $\begin{array}{l}0.03 \\
0.04\end{array}$ \\
\hline 2 Sigs. agree & $\begin{array}{l}\text { Low seq.> }>\text { Low sim. } \\
\text { High seq. }>\text { High sim. }\end{array}$ & $\begin{array}{r}-7.33 \\
0.15\end{array}$ & $\begin{array}{r}4.37 \\
-0.46\end{array}$ & $\begin{array}{l}0.09 \\
0.55\end{array}$ & $\begin{array}{l}0.04 \\
0.05\end{array}$ \\
\hline
\end{tabular}

we find significant support for this prediction in our comparisons, which are omitted from the table. When voting costs are low, both sequential and simultaneous voting should have almost the same informational efficiency (a slight difference is predicted when we combine across all signal realizations because of differences in signal realizations in the treatments), but when voting costs are high, sequential voting should provide more informational efficiency. We test the five possible comparisons for all signal configurations as well as cases broken down by the distribution of signals for 15 total comparisons (the comparisons reported and not reported). Because the probability of false significance is higher when making such multiple comparisons, we used the nonparametric procedure described by Benjamini and Hochberg (1995). Define $q^{*}$ as the desired minimum false discovery rate or FDR. If we rank the comparisons by their corresponding $p$-values, where 1 denotes the smallest and 15 the greatest and the rank is denoted by $i$, Benjamini and Hochberg show that rejection of only null hypotheses such that the $p$ value is less than $\left(\frac{i}{15}\right) q^{*}$ (which we label the $q_{\mathrm{FDR}}$ value in Table 4) controls the FDR at $q^{*}$ when the test statistics are independent. Benjamini and Hochberg (2001) further show that rejection of only null hypotheses such that the $p$-value is less than $\frac{\left(\frac{i}{15}\right) q^{*}}{\sum_{i} \frac{1}{i}}$ controls the FDR at $q^{*}$ when the tests have dependencies. We report results using both procedures in Table $4\left(q^{*}=0.05\right)$.

We find mixed results in our comparisons of sequential and simultaneous voting on informational efficiency. As expected, we find that in the low-cost case, there is no significant difference between sequential and simultaneous informational efficiency except when all three signals agree and sequential voting is slightly more efficient, although the result is only significant if we assume that the multiple tests are independent and the magnitude of the difference is very small $(0.05)$. The effect is due to greater than equilibrium abstention by low-cost voters in simultaneous voting. However, although we expect that in the high-cost case there will be a significant difference between sequential and si- multaneous informational efficiency, we again find only a significant difference when all three signals agree and only if we assume that the multiple tests are independent. This reflects the fact that high-cost voters vote more frequently than predicted in simultaneous voting. Our results suggest that informational efficiency is somewhat affected by the predicted variables but is also affected by behavioral factors that lead voters to diverge from Nash equilibrium predictions and, as we found earlier, is better explained by the quantal response model.

\section{Economic Efficiency}

We use as a benchmark in evaluating economic efficiency the total expected payoffs received by the groups. To compare the differences in economic efficiency between the sequential and simultaneous voting mechanisms with their predicted differences we calculated the predicted net expected group payoffs given the realized signals and expected Nash equilibrium behavior. Note that these are calculated before the realization of the state $A$ or $B$ so that any randomness in the state, conditional on signal draws, that might benefit a particular treatment, does not affect our comparisons. Furthermore, we calculated the payoffs received using the frequency of signal realizations and before the realization of the state in the same way. Finally, as with informational efficiency, we calculated the efficiency measure for the two different signal configurations (three agree and two agree). Similarly, we calculated the actual net expected group payoffs in the same fashion. Table 4 also presents the predicted differences in net expected benefits and our statistical comparisons (again we only report comparisons of voting mechanisms as the comparisons between lowand high-cost treatments are, although highly significant and in the predicted directions, not surprising). As with informational differences, we controlled for a false rejection rate of 0.05 under both the assumption that the multiple test statistics are independent and that they are dependent. 
In general, the Nash predicted differences in economic efficiency are supported by the comparisons and we find stronger differences in economic efficiency between the voting mechanisms than for informational efficiency. The Nash equilibrium predictions on the effects of voting mechanism on economic efficiency are different from those with respect to informational efficiency. That is, when three signals agree, sequential voting is predicted to be more economically efficient than the simultaneous mechanism, greatly so when voting costs are high. We find significant support for these predictions. But when only two signals agree, simultaneous voting is predicted to be more economically efficient when voting costs are low and very little difference in economic efficiency by voting mechanism is predicted when voting costs are high in this situation. In our empirical analysis, we find no significant difference by voting mechanism when only two signals agree regardless of the cost of voting. Again, these divergences from the Nash equilibrium prediction support the quantal response model of voter behavior as voters vote more than predicted when voting costs are high and less than predicted in the low-cost case.

Summarizing, the two main findings about efficiency are:

1. Sequential voting is slightly more informationally and economically efficient than simultaneous voting for both high and low voting costs, but the difference is only significant when all three signals agree and, in the case of informational efficiency, if we assume that the multiple tests are independent.

2. The most informationally efficient outcomes are observed in the low-cost sequential voting game, and the least informationally efficient in the highcost simultaneous game. The difference in efficiency between the two is estimated to be 13 percentage points across all cases, 17 percentage points when all three signals agree, and 12 percentage points when only two signals agree.

\section{EQUITY AND VOTING ORDER}

Later voters may have an unfair advantage over earlier voters because they abstain more, even in the highcost treatment where early voters are theoretically predicted to abstain strategically. As noted earlier, the inequity we address is inequity caused by the ability of voters to "free ride" on the participation of other voters and not inequities caused because policy outcomes may be more representative of the choices of those who participate. Is sequential voting inequitable in this sense? Do later voters earn greater payoffs? In Table 5 we compare the expected mean payoffs in sequential voting by voter position and treatment with the Nash predicted differences, again controlling for a false discovery rate $\left(q^{*}=0.05\right)$ and for both independent tests and multiple dependencies. We find that there are significant differences between voter payoffs in the sequential voting games, second and third voters are significantly better off first voters in the low- and high-cost treatments, and third voters make significantly more than second voters in the low-cost treatment. Thus, we find significant evidence that sequential voting procedures in this setting favor later voters. We also find significant evidence that second and third voters make more on average than simultaneous voters in the low-cost treatment and in the high-cost treatment when three signals agree. Thus, being later in the voter order provides a greater expected payoff than in simultaneous voting.

We also find that some of the Nash predicted differences in payoffs are not supported in the data largely because of the divergence from Nash behavior in abstention decisions. In the high-cost treatment, first and second voters are predicted in the Nash equilibrium to make significantly more than simultaneous voters. However, because first voters vote more than predicted, there is no significant difference between these payoffs. Furthermore, first voters actually made significantly less than second and third voters, which is contrary to the Nash prediction but consistent with the quantal response model.

\section{CONCLUDING REMARKS}

Many voting situations from school board meetings to referenda on the European Union's Constitution to mass elections in the United States are not simultaneous. The choices made by earlier voters are often known to those who vote later in the sequence. Despite popular perception that sequence matters in these voting situations, there has been little theoretical or empirical study of the effect of sequence on voter information and the outcomes of voting. In this paper we provide a theoretical and experimental examination of the two systems under costly voting. Our theory suggests that when the cost of voting is low, early voters should participate and later voters should only participate if their votes are pivotal; that is, they should strategically abstain when not pivotal. In contrast, our theory suggests that when the cost of voting is high, we are likely to observe strategic abstention by early voters as they "pass" the decision on to later voters.

Our experiment allowed us to directly measure the effect of sequence on voter choices, including abstention, controlling for voter preferences and information, which is difficult using naturally occurring data. The results support the theoretical predictions in general. Not surprisingly, in simultaneous voting abstention increases with voting costs. However, we found that in simultaneous voting elections abstention is higher than predicted when costs are low and lower than predicted when costs are high, consistent with QRE. We largely found support for our comparative static predictions in sequential voting elections. There were two surprising findings: early voters abstain less than predicted when voting costs are high; late voters abstain more than predicted when their votes could be pivotal in both the low- and high-cost treatments.

We also considered the efficiency of sequential versus simultaneous voting when voting is costly. We found 


\begin{tabular}{|c|c|c|c|c|c|c|}
\hline \multirow[b]{2}{*}{ Cost } & \multirow[b]{2}{*}{ Cases } & \multirow[b]{2}{*}{ Comparison } & \multicolumn{2}{|c|}{ Difference } & \multirow[b]{2}{*}{$\mathrm{p}$} & \multirow[b]{2}{*}{$q_{F D R}$} \\
\hline & & & Nash & Actual & & \\
\hline \multirow{18}{*}{ Low } & All & Voter $1>$ Voter 2 & -1.6 & $-0.4^{* *}$ & 0 & 0.001 \\
\hline & & Voter $1>$ Voter 3 & -2 & $-0.77^{* *}$ & 0 & 0.001 \\
\hline & & Voter $1>$ Sim. & 0.16 & 1.54 & 0.04 & 0.03 \\
\hline & & Voter $2>$ Voter 3 & 0 & $-0.37^{* *}$ & 0 & 0.001 \\
\hline & & Voter 2>Sim. & 1.76 & $1.94^{*}$ & 0.02 & 0.03 \\
\hline & & Voter 3>Sim. & 1.76 & $2.31^{* *}$ & 0.01 & 0.02 \\
\hline & 3 Sigs agree & Voter $1>$ Voter 2 & -2 & $-0.64^{* *}$ & 0 & 0.001 \\
\hline & & Voter $1>$ Voter 3 & -2 & $-1.21^{* *}$ & 0 & 0.001 \\
\hline & & Voter $1>\operatorname{Sim}$ & 0 & 1.65 & 0.032 & 0.031 \\
\hline & & Voter $2>$ Voter 3 & 0 & $-0.57^{* *}$ & 0 & 0.001 \\
\hline & & Voter $2>\operatorname{Sim}$ & 2 & $2.29^{* *}$ & 0.01 & 0.02 \\
\hline & & Voter $3>$ Sim. & 2 & $2.86^{* *}$ & 0.001 & 0.02 \\
\hline & 2 Sigs agree & Voter $1>$ Voter 2 & -1.33 & $-0.24^{*}$ & 0.0137 & 0.014 \\
\hline & & Voter $1>$ Voter 3 & -2 & $-0.48^{* *}$ & 0 & 0.001 \\
\hline & & Voter $1>\operatorname{Sim}$ & 0 & 1.22 & 0.13 & 0.04 \\
\hline & & Voter $2>$ Voter 3 & 0 & $0.23^{*}$ & 0.01 & 0.02 \\
\hline & & Voter $2>\operatorname{Sim}$ & 1.33 & 1.46 & 0.09 & 0.04 \\
\hline & & Voter $3>$ Sim. & 1.33 & 1.69 & 0.06 & 0.04 \\
\hline \multirow[t]{18}{*}{ High } & All & Voter $1>$ Voter 2 & 0 & $-1.63^{* *}$ & 0 & 0.01 \\
\hline & & Voter $1>$ Voter 3 & 8 & $-1.9^{* *}$ & 0 & 0.01 \\
\hline & & Voter $1>\operatorname{Sim}$ & 13.54 & -0.03 & 0.49 & 0.05 \\
\hline & & Voter $2>$ Voter 3 & 8 & -0.28 & 0.19 & 0.04 \\
\hline & & Voter $2>$ Sim. & 13.54 & 1.59 & 0.06 & 0.03 \\
\hline & & Voter $3>$ Sim. & 5.54 & 1.87 & 0.033 & 0.032 \\
\hline & 3 Sigs agree & Voter $1>$ Voter 2 & 0 & $-2.24^{* *}$ & 0 & 0.01 \\
\hline & & Voter $1>$ Voter 3 & 8 & $-2.41^{* *}$ & 0 & 0.01 \\
\hline & & Voter $1>\operatorname{Sim}$ & 17.09 & 1.66 & 0.11 & 0.04 \\
\hline & & Voter $2>$ Voter 3 & 8 & -0.18 & 0.35 & 0.05 \\
\hline & & Voter $2>$ Sim. & 17.09 & $3.9^{* *}$ & 0.003 & 0.02 \\
\hline & & Voter $3>$ Sim. & 9.09 & $4.07^{* *}$ & 0.002 & 0.02 \\
\hline & 2 Sigs agree & Voter $1>$ Voter 2 & 0 & $-1.17^{*}$ & 0.007 & 0.02 \\
\hline & & Voter $1>$ Voter 3 & 8 & $-1.52^{* *}$ & 0.0003 & 0.02 \\
\hline & & Voter $1>\operatorname{Sim}$ & 11.05 & -1.05 & 0.2 & 0.04 \\
\hline & & Voter $2>$ Voter 3 & 8 & -0.35 & 0.2 & 0.04 \\
\hline & & Voter $2>$ Sim. & 11.05 & 0.12 & 0.5 & 0.05 \\
\hline & & Voter $3>$ Sim. & 3.05 & 0.47 & 0.35 & 0.05 \\
\hline
\end{tabular}

that although some predicted efficiency differences among treatments were significant, others were not, reflecting the divergence from Nash equilibrium behavior in individual voting decisions. We found evidence that sequential voting is somewhat more efficient informationally and economically than simultaneous voting. The evidence was strongest when all voters received the same signal and weakest when voters received different signals. Finally, we evaluated the equity of sequential voting. As predicted, there are significant advantages to later voters in sequential voting in the low-cost treatment, but these gains are at the expense of early voters. Although in the highcost sequential treatment earlier voters are predicted to benefit, we found evidence of the opposite effect; later voters make significantly more. Furthermore, we found that second and third voters make significantly more than voters in the simultaneous game in the low-cost treatment, but no significant difference in the high-cost treatment.
Our results thus yield mixed conclusions about the benefits of sequential over simultaneous voting, depending on how one weighs efficiency versus equity. There is some evidence that sequential voting is both informationally and economically more efficient, but nonequilibrium behavior of the voters makes these differences weaker than theoretically predicted and the differences are strongest when voters' information is identical. In sequential voting there are significant advantages to voters who are later in the voting order because they have the option of strategically abstaining after observing the earlier voters.

\section{APPENDIX}

\section{Proof of Proposition 2}

Consider the first case in which $\gamma \in[2 p(1-p), 1]$. We proceed in three steps: 
Step 1. Consider first voter 3 and assume, without loss of generality, that he has observed signal $a$. Only three cases are possible. If no other voter has voted, or if the number of voters who voted $A$ is equal to the number of voters who voted for $B$, then his posterior probability that the state is $A$ would be $p$. The net benefit of voting in this case is $(1-\gamma) \frac{1}{2}(2 p-1)>0$ : so he would vote informatively. The second case is when $A$ has received exactly one vote more than the other (histories $\phi A$ and $A \phi)$. In this case, the posterior belief that the state is $A$ is larger than $p$, and he would like $A$ to win; however, he does not need to vote to obtain this outcome, so he abstains. If, on the contrary, $B$ has received one vote more than $A$ from previous voters, then we have two distinct cases. In history $\phi B$, he believes that $A$ and $B$ have received the same number of signals. In this case, his posterior that the state is $\frac{1}{2}$ : the voter is indifferent between the options and would not vote (given that voting is costly). After history $B \phi$, he believes that $\mathrm{B}$ has received two votes (see Table 3 for details on out-of-equilibrium strategies), so he prefers alternative B and he abstains. Finally, it is possible that one alternative has received more than one vote more that the other: in this case voter 3 abstains because he would not affect the outcome.

Step 2. Consider now voter 2. We can distinguish two different cases. Assume first that voter 1 has not voted before. If voter 2 votes, then, by step 1 , he knows that voter 3 would abstain: his expected utility would be $(1-\gamma) \frac{1}{2}(2 p-1) v$. If he abstains, then voter 3 would vote informatively, and his expected utility would be $\frac{1}{2}(2 p-1) v$ : so he finds it optimal to abstain. Assume now that voter 1 has voted $A$. If voter 2 has observed signal $a$, then he would find it strictly optimal to abstain: in this case by voting $A$ would not affect the outcome and by voting for $B$ he would reduce the expected payoff. Assume that voter 2 has observed signal $b$. If he does not vote, then 3 would not vote as well and $A$ would win: his expected utility would be $\frac{1}{2} v$ (his posterior is $1 / 2$ in this case). Clearly voting for $A$ is suboptimal, so consider the other alternative in which he votes for $B$. In this case, by step 1 , voter 3 would vote informatively and decide the outcome of the election; and the net expected payoff would be $p v-c$. The net benefit of voting is therefore $(1-\gamma) \frac{1}{2}(2 p-1) v>0$, so voter 2 finds it optimal to vote informatively for $B$.

Step 3. Finally consider voter 1. If she abstains, then voter 2 would abstain. Voter 3 would vote informatively and determine the election: in this case the expected payoff would be $p v$. If she votes informatively, then she obtains

$$
p[p+(1-p) p] v+(1-p)\left[p^{2} v\right]-c .
$$

The net benefit of voting is therefore

$$
\left[p(1-p)-\frac{\gamma}{2}\right](2 p-1) v
$$

If $\gamma>2 p(1-p)$, voter 1 abstains and the election is decided by the last voter.

Consider now the second case in which $\gamma \in[0,2 p(1-p)]$. Assume that 2 and 3 follow exactly the same strategies as in (i), but 1 voters informatively. From steps 1 to 3 , this strategy is an equilibrium when $\gamma \leq 2 p(1-p)$. The result stated in Proposition 1 follows immediately, remembering that $\gamma=$ $c[(2 p-1) v]^{-1}$.

\section{REFERENCES}

Ali, Nageeb, and Navin Kartik. 2006. "A Theory of Information Cascades in Sequential Voting." Working paper, University of California at San Diego.
Bartels, Lawrence. 1988. Presidential Primaries and the Dynamics of Public Choice. Princeton, NJ: Princeton University Press.

Battaglini, Marco. 2005. "Sequential Voting with Abstention." Games and Economic Behavior 51 (May): 445-63.

Battaglini, Marco, Rebecca Morton, and Thomas Palfrey. 2005. "Efficiency, Equity, and Timing in Voting Mechanisms." Working paper, Princeton University, Princeton, NJ.

Benjamini, Yoav, and Yosef Hochberg. 1995. "Controlling the False Discovery Rate: A Practical and Powerful Approach to Multiple Testing." Journal of the Royal Statistical Society. Series B (Methodological) 57 (1): 289-300.

Benjamini, Yoav, and Daniel Yekutieli. 2001. "The Control of the False Discovery Rate in Multiple Testing under Dependency." The Annals of Statistics 29 (August): 1165-1188.

Bikhchandani, Sushil, David Hirshleifer, and Ivo Welch. 1992. "A Theory of Fads, Fashion, Custom, and Cultural Change as Informational Cascades." Journal of Political Economy 100 (October): 992-1026.

Borgers, Tilman. 2004. "Costly Voting.” American Economic Review 94 (March): 57-66.

Callander, Steven. 2004. "Bandwagon and Momentum in Sequential Voting." Mimeo. MEDS, Northwestern University.

Camerer, Colin, Thomas Palfrey, and Brian Rogers. 2006. "Heterogeneous Quantal Response Equilibrium and Cognitive Hierarchies." Social Science Working Paper \# 1260, Caltech.

Canes-Wrone, Brandice, Michael C. Herron, and Kenneth W. Shotts. 2001. "Leadership and Pandering: A Theory of Executive Policymaking." American Journal or Political Science 45 (July): 53250.

Cohen, Linda R., and Roger G. Noll. 1991. "How to Vote, Whether to Vote: Decisions About Voting and Abstaining on Congressional Roll Calls." Political Behavior 13 (June): 97-127.

Dekel, Eddie and Michele Piccione. 2000. "Sequential Voting Procedures in Symmetric Binary Elections." Journal of Political Economy 108 (February): 34-55.

Feddersen, Timothy and Wolfgang Pesendorfer. 1997. "Voting Behavior and Information Aggregation in Elections with Private Information." Econometrica 65 (September): 1029-58.

Fey, Mark. 1998. "Informational Cascades and Sequential Voting." Mimeo. University of Rochester, Dept. of Political Science.

Frankovic, Kathleen. 2001. "Historical Perspective." In CBS News Coverage of Election Night 2000: Investigation, Analysis, Recommendations, report prepared by Linda Mason, Kathleen Frankovic, and Kathleen Hall Jamieson for CBS News, pp. 5185 .

Gerardi, Dino, and Leeat Yariv. 2006. "Deliberative Voting.” Journal of Economic Theory in press.

Glazer, Amihai, Robert Griffin, Bernard Grofman, and Martin Watenberg. 1995. "Strategic Vote Delay in the U.S. House of Representatives." Legislative Studies Quarterly 20 (February): 3745.

Guarnaschelli, Serena, Richard McKelvey, and Thomas Palfrey. June 2000. "An Experimental Study of Jury Decision Rules." American Political Science Review 94 (2): 407-424.

Hung, Angela, and Charles Plott. 2000. "Information Cascades: Replication and Extension to Majority Rule and Conformityrewarding Institutions." American Economic Review 91 (December): 1508-20.

Jackson, John. 1983. "Election Night Reporting and Voter Turnout." American Journal of Political Science 27 (November): 615-35.

Jones, David R. 2003. "Position Taking and Position Avoidance." Journal of Politics 65 (August): 851-63.

Krasa, Stefan, and Mattias Polborn. 2005. "Is Mandatory Voting Better Than Voluntary Voting." Working paper. University of Illinois.

McKelvey, Richard, and Thomas Palfrey. 1995. "Quantal Response Equilibria for Normal Form Games." Games and Economic Behavior 10 (July): 6-38.

McKelvey, Richard, and Thomas Palfrey. 1998. "Quantal Response Equilibria for Extensive Form Games." Experimental Economics 1 (1): 9-41.

Morton, Rebecca B., and Kenneth C. Williams. 1999. "Information Asymmetries and Simultaneous versus Sequential Voting." American Political Science Review 93 (March): 51-67.

Morton, Rebecca B., and Kenneth C. Williams. 2000. Learning by Voting: Sequential Choices in Presidential Primaries and Other Elections. Ann Arbor, MI: University of Michigan Press. 
Poole, Keith, and Howard Rosenthal. 1997. Congress: A PoliticalEconomic History of Roll-Call Voting. New York: Oxford University Press.

Rothenberg, Lawrence, and Mitchell Sanders. 1999. "Rational Absention and the Congressional Vote Choice." Economics and Politics 11 (November): 311-40.

Rothenberg, Lawrence, and Mitchell Sanders. 2000. "Legislator Turnout and the Calculus of Voting: The Determinants of Abstention in the U.S. Congress." Public Choice 103 (June): 259-70.
Shepard, Alicia C. 2001. "How They Blew It," American Journalism Review 23 (January/February): 20-27.

Thomas, Martin. 1991. "Issue Avoidance: Evidence from the U.S. Senate." Political Behavior 13 (March): 1-20.

Thompson, Dennis F. 2004. "Election Time: Normative Implications of Temporal Properties of the Electoral Process in the United States." American Political Science Review 98 (February): 51-64.

Wit, Jorgen 1997. "Herding Behavior in a Roll-Call Voting Game." Mimeo. CREED, Dept. of Economics, University of Amsterdam. 